\title{
A BAIXA DEMANDA AOS CURSOS DE ENFERMAGEM - UM PERFIL DA PROFISSÃO TRAÇADO PELOS JOVENS*
}

\author{
Silvana Martins Mishima** \\ Maria Cecilia Puntel de Almeida***
}

MISHIMA, S. M.; ALMEIDA, M. C. P. A baixa demanda aos cursos de Enfermagem - um perfil da profissão traçado pelos jovens. Rev. Esc. Finf. USP, v. 28, n. 2, p. 137-46, ago. 1994

Este estudo, de caráter descritivo exploratório, objetivou identificar a percepçāo que os jovens, que estão terminando o $2^{\circ}$ grau, têm acenca dos fatores que possivelmente vèm. influénciando no processo de escolha profissional para a Enfermagem. Foi possivel identificar um perfil parcial para esta profissão, pouco atrativo para que os jovens optem por ela.

UNITERMOS: escolha profissional, demanda para cursos de Enfermagem.

\section{INTRODUÇÃO}

A questão quantitativa da força de trabalho em enfermagem. principalmente do enfermeiro, no que se refere ao número de ingressantes aos cursos de enfermagem e ao número de egressos, tem estado presente no transcorrer da história da enfermagem brasileira, de formas mais ou menos acentuadas, de acordo com periodos históricos específicos.

Quando se instalou a enfermagem moderna no Brasil, na década de 20 , esta não era uma preocupaçāo tão fundamental, uma vez que se procurava garantir a formação de profissionais devidamente qualificados e profissionalmente competentes, independente da questão numérica ${ }^{10}$.

Contudo já em 1949, começou-se a discutir a carência de pessoal de enfermagem para os serviços de saúde e a necessidade de aumentar este contingente de trabalhadores (VERDERESE) ${ }^{11}$. Na primeira investigação realizada em nível nacional, em 1956, o Levantamento de Recursos e Necessidades em Enfermagem ${ }^{2}$, são reconhecidas as dificuldades enfrentadas pelos profissionais quanto às suas condições de trabalho, rotatividade, a baixa demanda para os cursos de graduaçāo, alta evasão profissional. Tais problemas, de uma forma até mais intensa, se fazem presentes nos dias de hoje.

\footnotetext{
- Extraido da Dissertação de Mestrado apresentada à Escola de Enfermagem de Ribeirảo Preto da Universidade de Sło Paulo.

- Enfermeira. Mestre em Enfermagem. Professor Assiatente junto ao Departamento de Enfermagem Materno Infantil e Saúde Pública da Escola de Enfermagem de Ribeiráo Preto - USP.

*** Enfermeira. Professor Titular junto ao Departamento de Enfermagem Materno Infantil e Saude Pública da Escola de Enfermagem de Ribeirảo Preto. USP.
} 
Desta forma, pode-se observar que a questão da baixa demanda aos cursos de enfermagem não é um fenômeno recente; tem origem na própria origem da enfermagem moderna, sendo constatada e discutida em diferentes momentos $1,2,3,6,11$.

Em 1986, a Escola de Enfermagem de Ribeirāo Preto da Universidade de São Paulo identificou o problema do baixo ingresso ao curso de graduação, quando, das 80 vagas oferecidas no concurso vestibular, apenas 12 foram preenchidas. Tal situação repetiu-se nos anos de 1987, 1988 e 1989. Contudo, este nāo foi o único momento em que tal situação ocorreu nesta instituição.

Se tomados os 36 anos (1953 à 1989) de existência da Escola de Enfermagem de Ribeirão Preto, pode-se verificar que de 1953 à 1968 o número de vagas preenchidas, em média nāo atingia metade das vagas oferecidas, Isto novamente, ocorreu a partir de 1986, quando houve uma ociosidade de vagas que chegou a $85 \%$. Estes dados podem ser observados no GRÁFICO I.

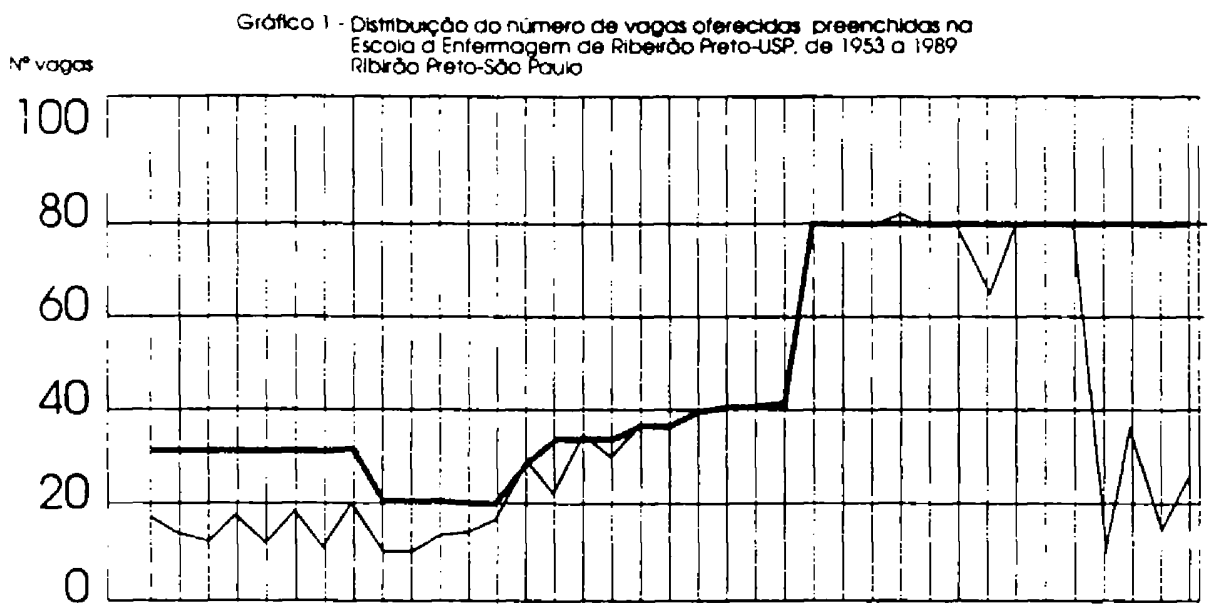

53545556575859000102036405006708097071727374757677787980818283848580878889

\section{Vagas oferecidas}

\section{Vagas preenchidas}

É importante que se atente para a distribuição existente entre os dois períodos em que não houve preenchimento integral do número de vagas oferecidas. O primeiro momento caracterizou-se por uma escassez de jovens interessados em cursar enfermagem na Escola de Enfermagem de Ribeirão Preto, e por uma ação intensa de divulgar tanto a profissão quanto a instituição, visando atrair jovens para o curso. Esta ação baseava-se nos moldes eštão empreendidos por outras escolas de enfermagem brasileiras e pela Associação Brasileira de Enfermagem. 
Neste mesmo período começou, por volta de 1962 , a haver o aumento do número de ingressantes, fato que coincidiu com o enquadramento da enfermagem como profissão liberal e como carreira de nível universitário. Ainda em 1968, passou a haver preenchimento integral do número de vagas oferecidas.

Entre 1968 e 1985, ocorreu preenchimento integral do número de vagas e ao mesmo tempo um aumento da demanda para o curso na Escola de Enfermagem de Ribeirão Preto. Este aumento da demanda pode ser evidenciado pela relação candidato/vaga que sofreu alterações no período. Em 1968 havia 0,9 candidatos por vaga e em 1974, passou a haver 4,4 candidatos por vaga, sendo que em 1976 dobrou-se o número de vagas oferecidas pela Escola, passando de 40 para 80 . Este número se deu em função, principalmente, das pressões de mercado de trabalho para maior absorção do profissional enfermeiro na cidade e região de Ribeirão Preto (Estado de São Paulo - Brasil).

Desta forma, é possível afirmar que a situaçāo do curso de enfermagem na Escola de Enfermagem de Ribeirão Preto - USP caracterizou-se inicialmente por:

- Baixa demanda ao curso, possivelmente em função do desconhecimento da sociedade ribeirãopretana do profissional enfermeiro, aliado a um mercado de trabalho pouco explorado, caracterizado pela ausência deste profisssional neste mercado (de 1953 até em torno de 1962);

- Aumento progressivo da demanda (a partir de 1962) com preenchimento do número de vagas oferecidas (de 1968 a 1985);

- queda da demanda para o curso, já a partir de 1984 e evidenciada em termos de não preenchimento das vagas oferecidas em 1986, agora muito provavelmente como reflexo de uma forte determinação das condições do mercado de trabalho para o enfermeiro.

É importante atentar ao fato de que a situação vivida pela referida escola nāo lhe foi específica e que a queda do número de ingressantes aos cursos de enfermagem também se deu, em maior ou menor intensidade, em outras escolas de enfermagem brasileiras. Mesmo na ausência de informações mais sistematizadas em relação ao problema, e embora se tivesse dados apenas de um pequeno número de escolas, a situação era preocupante, uma vez que foi possível detectar o mesmo problema em escolas altamente conceituadas no contexto educacional brasileiro neste setor.

Traçado este perfil da situação encontrada na Escola de Enfermagem de Ribeirão Preto, cabe explicitar que, neste estudo, pretendeu-se fazer uma primeira aproximação a este objeto de investigação, em um momento e lugar específicos, através de um levantamento de opiniões dos jovens que estão se preparando, nas instituiçōes de $2^{\circ}$ grau (nível médio), para ingressarem na universidade, acerca de sua possível opção profissional.

Objetivou-se identificar algumas variáveis que poderiam estar influenciando a escolha da profissão de enfermagem, quais sejam: informaçāo, 
vocação, nivel de preparação nos estudos, condiçōes do exercício profissional, mercado de trabalho, "status" social, trabalho feminino, possibilidade de ascensão profissional e atividade liberal.

Assim este trabalho efetivamente não se direcionou para uma abordagem qualitativa, ou seja, de compreender o problema em suas diferentes dimensões, mas através de um levantamento quantitativo de opiniões, estabelecer relaçōes entre as variáveis estudadas, de forma a obter um panorama geral de qual seria a percepção destes jovens acerca de questōes ligadas à opção profissional em geral e a profissão de enfermagem em particular.

\section{TRAJETÓRIA DA PESQUISA}

... Este estudo; de caráter exploratório descritivo, não teve a intenção de apresentar as determinaçōes e prescrever soluçōes a curto, médio e longo prazos para a correção do problema, mas objetivou trazer a discussão alguns fatores que certamente vêm influenciando a baixa demanda aos cursos de enfermagem.

Para tanto buscou-se levantar as variáveis que possivelmente estariam presentes na escolha profissional junto aos jovens academicamente preparados a ingressar na universidade.

A população de referência constitui-se dos jovens que em 1989, cursavam o $3^{\circ}$ ano do segundo grau, tanto das escolas públicas quanto privadas do município de Ribeirão Preto, bem como dos cursos preparatórios para 0 concurso vestibular.

Foi realizada a amostragem por conglomerados, sendo estes compostos pelas escolas. As escolas foram selecionadas em 4 estratos - escola pública, escola privada, escola privada com curso preparatório anexo, curso preparatório para o vestibular. Esta estratificaçāo foi assim realizada em virtude. principalmente, da origem diferenciada dos jovens que se dirigem a cada instituição de ensino. Em última análise, este critério de classificação foi uma tentativa de estratificar socialmente os jovens que compunham cada estrato considerado, a partir de sua inserção em uma instituição de ensino, uma vez que esta se dá, sobretudo em função da classe social a que pertence o jovem, de suas perspectivas em relação à formação escolar, de suas possibilidades financeiras, etc.

A seleção das unidades amostrais (classes) dentro de cada conglomerado (escola) e conseqüentemente e de cada estrato, foi casual simples sem reposição.

Dentro de cada estrato foram selecionadas $10 \%$ das classes existentes num total de 10 classes (entre período diurno e noturno) e 298 jovens.

Utilizou-se, como instrumento para coleta de dados, um questionário, onde se buscou conhecer a opinião dos jovens através das variáveis consideradas e a partir das mesmas traçar um esboço, ou seja, um perfil parcial para a profissão enfermagem. 
A amostra constou de 298 jovens, 157 do sexo masculino e 141 do sexo feminino, perfazendo respectivamente 52,9 e 47,3\%. De modo geral esse grupo de jovens poderia ser assim identificado: em sua maioria $(58,0 \%)$, eram jovens que estudavam no periodo diurno (sendo que, mais frequentemente, os do grupo masculino estudavam no periodo noturno), estavam em uma faixa etária que variou dos 16 aos 18 anos (com exceção dos jovens que compunham o estrato 4, que constituiu o grupo mais velho, com idades que variava dos 18 aos 22 anos) e frequientemente não exerciam nenhuma atividade laboral $(64,8 \%)$. Os jovens que trabalhavam, exerciam, na maioria das vezes, atividades manuais assalariadas (balconistas, auxiliar de serviços gerais, industriários, etc), ou seja, atividades que normalmente não exigem qualificação especifica. Para a categorização das atividades laborais foram agrupadas segundo a categorização de PEREIRA ${ }^{9}$, modificada por Pelá ${ }^{7,8}$.

Seus pais, frequentemente dedicavam-se a atividades não manuais assalariadas (vendedores, funcionários públicos, representantes comerciais, professores, etc.) e as mães, na maioria, não exerciam atividade profissional fora do lar. Quanto a instrução, tanto para os pais como para as mães, esta se concentrou no primeiro grau incompleto, havendo um deslocamento para o segundo grau completo.

Esta descrição foi pertinente aos jovens que compunham os estratos 1 (escola pública), 2 (escola provada) e 4 (curso preparatório para o vestibular).

Os jovens do estrato 3 (escola privada com curso preparatório para o vestibular anexo), em sua maioria, estudavam no periodo diurno, enquadravam-se na faixa de 16 aos 18 anos $(85,7 \%)$ e não trabalhavam. Seus pais mais freqüentemente exerciam atividades nāo manuais não assalariadas (fazendeiros, pecuaristas, profissionais liberais, etc) e possuíam uma formaçăo universitária completa. Já as mães dos jovens deste grupo, exerciam freqüentemente atividades fora do lar não manuais assalariadas e não manuais não assalariadas, e contavam, em sua maioria, com formaçăo universitária completa.

Pode-se portanto constatar que o estrato 3 apresentou uma caracterização diversa daquela observada para os demais estratos.

Verificando-se a experiência anterior dos jovens em concursos vestibulares (seleção para ingresso em cursos de nivel universitário) observou-se que dos 298 jovens selecionados, $117(39,3 \%)$ já haviam prestado algum exame vestibular, e que destes $63(53,8 \%)$ ainda estavam a cursar o segundo grau. Isto significa que $53,8 \%$ dos jovens que já tinham experiência anterior em concurso vestibular, no momento que o prestaram, não estavam habilitados para tal, ou seja, nāo tinham concluído o segundo grau.

Enfermagem e Medicina foram as carreiras mais procuradas por estes jovens, em suas tentativas anteriores em exames vestibulares. Contudo, chama atenção o fato de que $\mathbf{8 2 , 4 \%}$ dos jovens que prestaram vestibular para a Enfermagem não estavam habilitados para tal, ou seja, nāo haviam conciuído o segundo grau, enquanto que para a Medicina 57,9\% já haviam concluído 
o segundo grau, estando aptos academicamente para prosseguir os estudos de nivel universitário.

Assim, parece lícito dizer que a Enfermagem, neste momento, se constitui em uma "carreira teste" (este termo procura traduzir a idéia de carreiras existentes no exame vestibular que possibilitam ao vestibulando fácil acesso às provas de seleção do vestibular, por apresentarem uma nota de corte baixa), uma vez que a maioria dos jovens que já haviam prestado o exame vestibular para esta carreira, o fizeram sem estarem habilitados para cursala.

Com relação as variáveis tratadas neste estudo - riqueza propiciada pelo exercício da profissão, desemprego, vocação, salários gratificantes, adequação ao sexo, exposição a riscos, rodízio de horários de trabalho, exercício liberal da profissão, preparação nos estudos, "status" social, dificuldade nos exames de ingresso, informação sobre a profissão, ascensão profissional - foi possível a partir da percepçāo dos jovens sobre tais variáveis, esboçar-se um perfil (segundo as perspectivas destes jovens) para a enfermagem. Tratou-se de um perfil parcial, um esboço, pois abrangeu apenas alguns aspectos que poderiam estar interferindo na tomada de decisão para a escolha profissional.

As variáveis consideradas neste estudo como fundamentais para traduzir uma aproximação ou afastamento em relação à enfermagem, foram apresentadas aos jovens dentro de um quadro de referência onde constavam juntamente com a enfermagem 5 outras profissōes. Ou seja, procurou-se verificar como os jovens dos diferentes estratos, percebiam cada uma das seguintes profissões: enfermagem, administração de empresas, arquitetura e urbanismo, medicina, jornalismo e química. As seis profissões escolhidas foram determinadas pelos seguintes critérios:

- por serem predominantemente masculinas ou femininas: administração de empresas, enfermagem, jornalismo;

- Por apresentarem elevado prestígio perante a sociedade e serem reconhecidamente "liberais": medicina, arquitetura e urbanismo;

- por sofrerem processo de esvaziamento no número de ingressantes: enfermagem e química;

- por apresentarem alta geração de empregos: medicina, administração de empresas, jornalismo.

É importante ressaltar que a opção por este rol de profissões, segundo os critérios estabelecidos, foi feita utilizando-se um estudo da Editora Abril, publicado anualmente 4,5 , onde são colocadas à disposição dos jovens, que estão a se dirigir para o vestibular, informações sobre as profissões que apresentam maior crescimento de oferta de empregos, salários, caracteristicas da prática profissional, etc.

Feitas tais consideraçōes, apresenta-se, a seguir o perfil delineado para a profissão de enfermagem, a partir da percepção dos jovens. Este perfil, como já explicitado, é parcial, pois abrangeu apenas alguns dos aspectos que poderiam estar interferindo na tomada de decisão na escolha desta profissão, 
e constituiu um estereótipo daquilo que os jovens consideravam a respeito da enfermagem. Este é definido a seguir:

A enfermagem é uma profissão que não proporciona riqueza a seus exercentes, e apesar de haver grande oferta de emprego, os salários são médios, tendendo a baixos ou muito baixos, no contexto das profissōes de nivel universitário. Para seu exercício é necessária muita vocação, sendo uma profissão mais adequada para as mulheres. Nas atividades diárias, inerentes à profissão, ocorre, freqüentemente a exposição a riscos de diferentes origens. É pequena a possibilidade de trabalho em turnos fixos. É praticamente inexistente a possibilidade de exercício liberal da profissão; esta apresenta um "status" médio na sociedade, havendo tendência a ser considerado baixo ou muito baixo. São pequenas as possibilidades de ascensão profissional. Seus estudos preparatórios e exames de ingresso são de dificuldade média, tendendo a serem considerados fáceis ou muito fáceis.

Cabe aqui frisar que de todas as profissōes consideradas, a enfermagem, para todos os estratos, foi a única em que quase nunca ou nunca existe a possibilidade de exercício liberal; esta foi basicamente a única variável que apresentou o mesmo padrão de respostas para todos os estratos considerados. Deve-se ressaltar que a possibilidade de exercício liberal indica uma das alternativas possiveis de inserção do indivíduo, não só no mercado de trabalho, como também na sociedade, e que acaba por interferir em outros aspectos pertinentes à profissāo (ganhos salariais, riqueza, "status").

Assim, parece lícito supor que tal variável apresentou-se como muito significativa neste perfil parcial traçado para a enfermagem, interferindo, de forma relevante, na rejeição da profissão pelos jovens.

Este perfil parcial apareceu, assim, delineado, em todos os estratos, embora no estrato 3 (escola privada com curso preparatório para o vestibular anexo), existisse certa ênfase em considerar a questão de baixos salários, pouca possibilidade de riqueza proporcionada pela profissão, baixo "status" da profissaao na sociedade, pequena dificuldade nos exames de ingresso. Ou seja, mais intensamente foram considerados os fatores ligados ao mercado de trabalho como limitantes para a escolha desta profissão.

Quanto as justificativas listadas para a resposta a uma possivel opção dos jovens para a profissão enfermagem, é necessário deixar claro que em funçāo do grande número de justificativas, foi preciso proceder-se a uma categorização das mesmas. Para tanto, tais justificativas foram englobadas em seis categorias distintas, dadas a seguir:

1. opiniōes pessoais negativas sobre a profissão, englobando características necessárias e importantes ao exercente da profissão, mas ao mesmo tempo limitantes (uma vez que o jovem pode não apresentar a caracteristica necessária): vocação, paciência, dedicação, etc.

2. opiniōes pessoais positivas sobre a profíssão, concernentes ao caráter humanitário da mesma, além da identificação de disciplinas, da preferência do jovem, que possivelmente estariam associadas à formação do enfermeiro. 
3. opiniōes negativas quanto às condições do exercício profissional e do mercado de trabalho, onde apareceram questões tais como salários, autonomia profissional, "status" da profissão na sociedade, etc.

4. opiniões positivas quanto às condições do exercicio profissional e mercado de trabalho.

5. opiniōes indiferentes, presentes nas justificativas que trataram de questōes como: falta de interesse pessoal, falta de identificação com a profissão, etc.

6. sem informação.

As justificativas contidas na categoria 1 distribuíram-se igualmente nos 4 estratos e constituem um forte componente negativo. Já as categorias 3 e 5 apareceram mais fortemente evidenciadas no estrato 3 .

De uma maneira geral, o que pode ser observado é que, dentro do conjunto de justificativas encontradas, parece haver um forte componente negativo, que limitaria a opção pela enfermagem. Exemplos destas justificativas:

Não gosto (ou não me sinto bem) de profissões ligadas a hospital. Não gosto de rodízios de horários/ sacrificios de horários.

Necessário ter vocaçāo e não a possuo.

Não satisfaz profissionalmente.

Ganha-se pouco/ salários baixos.

Interessante, é o fato de haver para todos os estratos (com exceção do estrato 3) um número significativo de justificativas que disseram respeito à necessidade de se ter vocação (ou a ausência dela no jovem) para o exercicio da profissão. Já no estrato 3 o maior número de justificativas ligam-se à questão do baixo salário reputado à profissão.

Ao que parece, os jovens do estrato 3 teriam uma preocupação mais próxima de questões objetivas de sobrevivência, de expectativas profissionais, etc, quando justificaram sua não preferência pela profissão calcada na questão salarial. Isto possivelmente ocorreu em função das características sócioeconômicas e culturais deste grupo, que o diferencia dos outros estratos.

Já nos demais estratos, que muito se assemelharam em suas características (apresentadas na identificação), a questão da vocação, do ideal profissional pareceu ser mais importante. Ao mesmo tempo, a questão da vocação para o exercício da enfermagem traz certo tom pejorativo, uma vez que parece ser esta imprescindível, em face a todo o sacrifício, abnegação, dedicação, necessários ao seu exercício profissional. Cabe frisar que a enfermagem é uma profissão tradicionalmente vista como requerendo inúmeros sacrifícios de seus exercentes, uma vez que o profissional lida com os sofrimentos do individuo doente. A própria figura de Florente Nightingale percorrendo os hospitais da Criméia com uma lamparina na mão, veiculada em livros e filmes, transmite idéia da profissão próxima ao sacerdócio, sendo portanto necessária muita vocação para seu exercício.

Tal concepção trazendo a idéia da vocação enquanto atributos, especiais inerentes a pessoa, que a faria enfrentar grandes exigências presentes na profissão, parece, ainda hoje, constituir-se em um juízo, um preconceito 
negativo em relação a mesma, traduzindo de alguma maneira, a percepção de que a enfermagem é uma profissão onde se depara com sacrificios, sofrimentos imensos, sendo que somente aquele com uma vocaçāo muito grande seria capaz de exercê-la.

Finalizando, é importante frisar que o instrumento para coleta de dados năo permitiu que a essência das justificativas fosse devidamente captada. $\mathrm{Ou}$ seja, em diferentes justificativas apenas o aparente foi captado, não sendo possivel identificar o que exatamente o jovem queria dizer.

Odeio enfermagem, a frase suscinta expressa por um jovem não oferece margem para se compreender o seu real significado.

\section{CONSIDERAÇÕES FINAIS}

É importante ressaltar que o presente estudo não é suficiente para explicar a totalidade da situação que se apresenta da baixa demanda aos cursos de Enfermagem. E antes de mais nada, um estudo exploratório, em que são discutidas algumas variáveis que possivelmente vêm interferindo neste processo.

A partir de tais variáveis, pode ser delineado um perfil para a profissāo de enfermagem. Este perfil, elaborado segundo as opiniōes dos jovens acerca destas variáveis tomadas para a enfermagem, é um perfil parcial, é um esboço, pois abrange apenas alguns aspectos que podem estar interferindo na tomada de decisão para a escolha desta profissão e que constitui um estereótipo daquilo que os jovens consideram para a Enfermagem.

Como já explicitado, por ser um estudo exploratório, algumas questões permanecem e mereceriam melhor tratamento em estudos posteriores que, utilizando alternativas metodológicas qualitativas, pudessem oferecer maiores explicações.

Desta forma, este estudo explicita um perfil parcial da profissāo de Enfermagem, porém não é suficiente para explicar as razóes do mesmo, sendo que a partir deste, investigaçōes fundamentadas nas ciências sociais devem ser realizadas na tentativa de buscar explicaçōes no campo do social e do cultural para a baixa demanda aos cursos de Enfermagem na sociedade brasileira.

MISHIMA.S. M.; ALMEIDA. M. C. P. The decreased demanda to the nursing courses - an outline for profession tracing for young people. Rev. Esc. Enf. USP, v. 28, n.2, p. 137-46, aug. 1994.

This study, which is based in a descriptive exploratory charater objetified to identify the perception that young people have concerning to the factors which possioly have been influencing the process of how to choose a professional career for nursing, been possibly to identify an outline for nursing. Outline, is not so atractive for the young people to select this profession.

UNITERMS: choose professional, demand to de Nursing courses. 


\section{REFERÊNCIAS BIBLIOGRÁFICAS}

ALCÂNTARA, G. A Enfermagem moderna como categoria profissional: obstáculos a sua expansāo na sociedade brasileira. Ribeirāo Preto, 1963, 117p. Tese(Cátedra)

- Escola de Enfermagem de Ribeirāo Preto, Universidade de Sảo Paulo.

ASSOCIAÇĀO BRASILEIRA DE ENFERMAGEM. Levantamento de recursos e necessidades em Enfermagem no Brasil, 1956-1958. Brasília, 1980.

FRANK C.M., Irmã. Atendendo as necessidades da enfermagem no Brasil. Rev.Bras.Enf. . v.13, n.3, p.349-61, 1960.

GUIA DO estudante: cursos \& profissōes. São Paulo, Editora Abrii, 1988.

cursos \& profissōes. Sāo Paulo, Editora Abril, 1989

MAIS ENFERMEIRAS para o País/Editorial/Rev.Bras.Enf. , v.10, n.5/6, p.513-4, 1966.

PELÁ, N.T.R. Contribuição ao estudo da assistência pré natal em um município paulista. Ribeirāo Preto, 1972.93p. Tese(Doutorado) - Escola de Enfermagem de Ribeirào Preto, Universidade de São Paulo.

Trauma mamilar e outros fatores mamários que interferem no aleitamento materno. Ribeirăo Preto, 1980, 213p. Tese(Livre-Docència) - Escola de Enfermagem de Ribeirão Preto, Universidade de São Paulo.

PEREIRA. L. O Magistério primário numa sociedade de classes. Sāo Paulo, Pioneira, 1969.

QUALIDADE ou quantidade?/Editorial/An.Enf. v.4, n.4, p.275-7, 1951.

VERDERESE, O. A Bahia e o problema da enfermagem. An.Enf., v.21, n.1, p.16-9, 1949. 